\title{
A Semi-quantitative Approach Development for Risk-based Inspection in a Petrochemical Plant
}

\author{
Davood Eskandari ${ }^{1}$, Hossein Charkhand ${ }^{2 *}$, Abdollah Gholami $^{3}$ \\ ${ }^{1}$ Department of Occupational Health and Safety, School of Public Health and Safety, Shahid Beheshti University of Medical \\ Sciences, Tehran, Iran; ${ }^{2}$ Department of HSE, Arya Sasol Petrochemical Company, Bushehr, Iran; ${ }^{3}$ Department of Occupational \\ Health, Social Determinant of Health Research Center, Faculty of Health, Birjand University of Medical Science, Iran
}

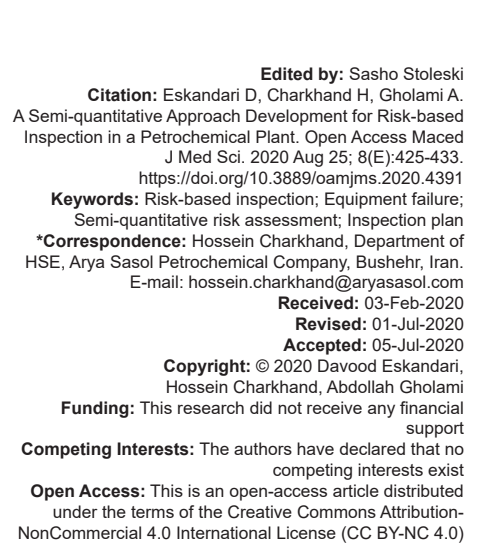

\section{Introduction}

Inspection is widely used in process industries to reduce the frequency of failures in fixed equipment, such as piping that is prone to damage the equipment in petrochemical plants [1], [2]. Performing inspection in the industry makes it possible to determine the conditions leading to irreparable events in terms of damage to persons, equipment, and the environment. By carrying out inspections, failure mechanisms can be identified, monitored, and controlled and then the time to failures around critical points can be estimated [3], [4], [5].

\section{Risk-based inspection (RBI)}

Different tools are available to assist decisionmakers to develop specific plans for inspections. One of these tools is the RBI method, which could be applied in chemical, petrochemical, refinery, oil, and gas industries. The successful implementation of RBI had been mentioned in multiple studies which were performed previously [6], [7], [8]. Based on Pareto prinzciple, about
$80 \%$ of equipment failures are associated with only $20 \%$ of equipment. Therefore, it would be an extremely useful action to provide a prioritized list of performed inspections (Figure 1). In RBI methodology, this priority is considered as the function of the risk of equipment failure and consequences of such failure [9], [10], [11]. In this work, the definition of risk from RBI aspect of view and way of its assessment would be discussed in more detail. This method enables industry owners to take into account a range of key factors in their decision-making processes, such as the level of reliability of equipment, as well as safety, health and the environment, and financial issues.

It is evident that the RBI methodologies have more advantages comparing to the conventional inspection methods. It is generally due to the risk assessment capability to provide more accurate data to evaluate the functionally status of the major components and then optimize the related operating and maintenance time scheduling [12], [13]. This method is a tool that helps to prioritize maintenance operations. The performed studies in power distribution systems have revealed that the most common system failures contributors are of a few high-risk components [14]. 


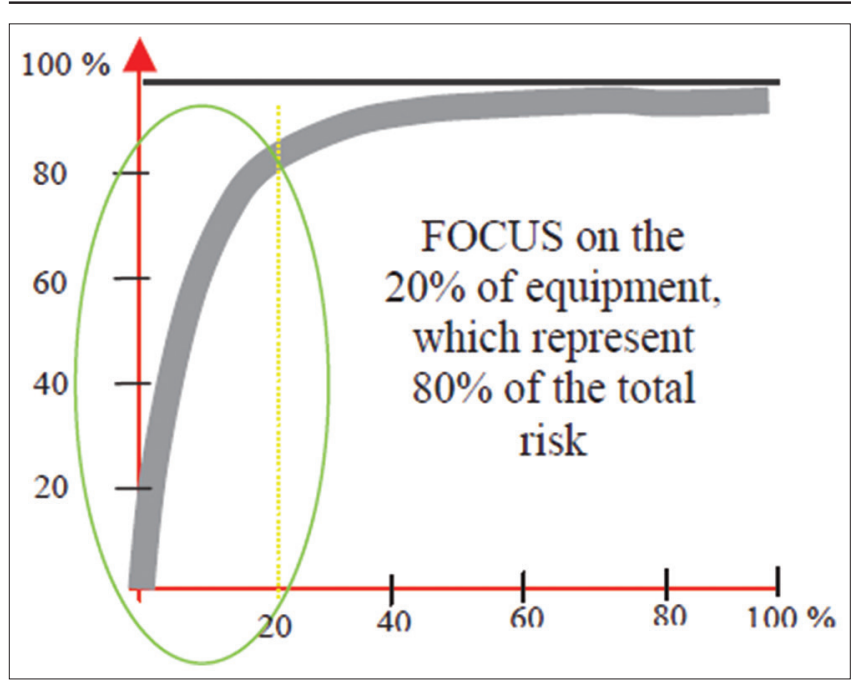

Figure 1: Total risk versus quantity of equipment

$\mathrm{RBI}$ is generally considered as a maintenance method relied upon risk analysis and is of high importance for prioritizing and organizing the maintenance activities on the equipmentures contributor's AR according to the obtained results from the conducted risk assessment, the RBI approach gives guidance on what, when, where, and how to inspect, and also, what should be documented.

There are different approaches to perform $\mathrm{RBI}$, reflecting variations in preferred methodology for demonstrating the material degradation and the probabilistic treatment. Some researchers promote an expert-based (subjective) methodology, for example, Kallen and Noortwijk, who approved a Bayesian approach for treatment errors in equipment wall thickness measurements [15]. Others prefer a more traditional frequency-based probability assessment approach. However, differences exist, the fundamental pillars are common; they are presented by accredited technical references such as API [16] and DNV [17]; also, Jovanovic [10], Kallen [18], and Khan et al. [19].

\section{Semi-quantitative RBI approach}

The RBI method can be used qualitatively, quantitatively, or by applying parts of both (i.e., semiquantitatively). Each methodology provides a systematic technique to display the risk, identify areas of concern, and create a prioritized list for a comprehensive inspection. Through these methods, each considers a risk ranking value to be applied for assessing separately the likelihood of failure (LOF) and the potential consequence of failure (COF). These two measures are then combined to estimate the risk of failure [7], [20]. Semi-quantitative RBI methodology gives us aspects resulting from both the qualitative and quantitative procedures. It facilitates to achieve the main benefits of both methodologies (e.g., precision of the quantitative and calculating speed of the qualitative). Usually, most of the data used in a quantitative methodology are required to this method but with fewer detail. The approach also may not be as rigorous as those applied for the quantitative methodology. The results are typically given in consequence and probability classifications or as risk scores, but numerical values may be related to each classification to permit the calculation of risk and the use of suitable risk acceptance measures. Figure 2 shows a typical RBI process from the latest edition of API RP 580 (2016) [21].

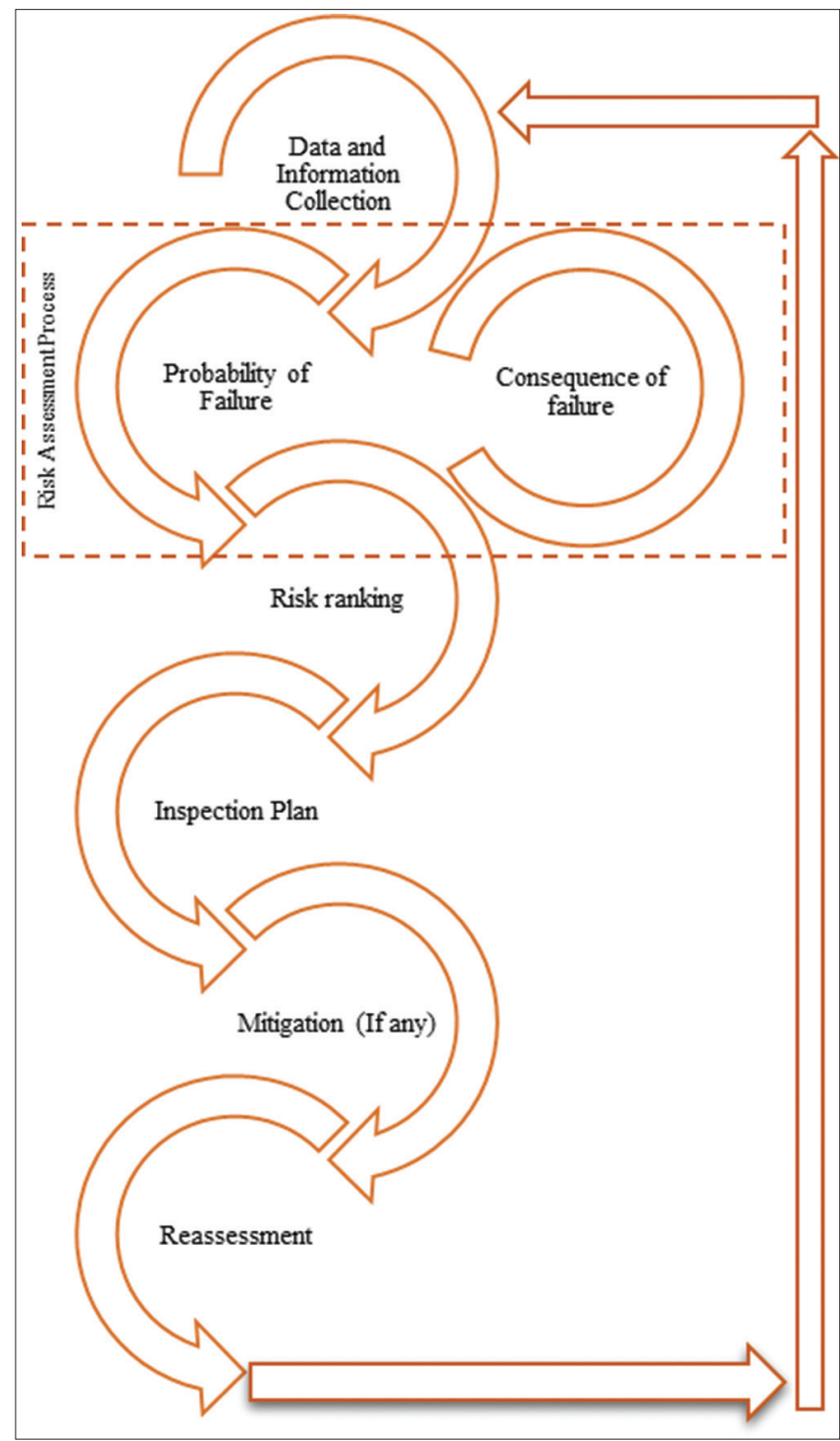

Figure 2: Risk-based inspection planning process (API RP 580)

\section{Study Methodology Materials and Methods}

The present study is conducted in Arya Sasol Polymer Company (ASPC), through its Olefin unit, and specifically on de-ethanizer section, which has 22 process equipment such as tower, pressure vessels, and exchangers. The RBI study performed by holding expert review meetings for each item specified in the project scope. 
Risk is the combination of the probability of an event occurring during a time period and the consequences (generally negative) associated with the event. In mathematical terms, risk could be calculated by the following equation:

\section{Risk $=$ Probability $\times$ Consequence}

This methodology applies to equipment failure likelihood based on API 581 standard; subsequently, the consequences of the failures of the equipment in "ASPC" are combined to estimate the related risk.

Below discusses the main two steps to estimate both the event consequence and related probability.

\section{Assessing COF}

The consequence, which represents the outcome of an event, is going to be estimated in a semi-quantitative approach. The COF associated with a particular item is assumed as a loss of containment which has already occurred. In this procedure, COF refers to COF and it ranges from 0 to 1 . The COF is used to represent the allocated value for consequence.

The COF consists of three factors, including safety, $\mathrm{C}_{\text {saf }}$ (up to $33 \%$ of total consequence), pollution, $\mathrm{C}_{\text {pol. }}$ (up to $17 \%$ of total consequence), and production, $\mathrm{C}_{\text {prod. }}$ (up to $50 \%$ of total consequence). Total consequence, based on these factors, is calculated using the following equation and Table 1 presents the classification for COF:

$$
\mathrm{C}=\frac{[\text { Casf }+ \text { Cpol }+ \text { Cprod }]}{12}
$$

$=$ Normalized consequence with value 0 to 1

Table 1: Consequence of failure classification

\begin{tabular}{ll}
\hline COF category & COF $(0-1)$ \\
\hline $\mathrm{N}$ & $0-0.2$ \\
$\mathrm{~L}$ & $0.2-0.4$ \\
$\mathrm{M}$ & $0.4-0.6$ \\
$\mathrm{H}$ & $0.6-0.8$ \\
$\mathrm{E}$ & $0.8-1$ \\
\hline COF: Consequence of failure. &
\end{tabular}

\section{Safety consequence factor $\left(C_{\text {saf }}\right)$}

This factor aims to consider the impact of a loss of containment or injury to personnel in the vicinity of the loss of containment. It consists of four parameters, including temperature $(\mathrm{Ft})$, pressure $(\mathrm{Fp})$, inventory ( $\mathrm{Fi})$, and inventory size (Fis). The amount of consequence associated with these parameters, i.e., temperature, pressure, inventory, and inventory size is calculated as below:

$$
\text { Csaf }=\frac{\mathrm{Ft} \times \mathrm{Fp} \times \mathrm{Fi} \times \mathrm{Fis}}{25}(\text { Max value }=4)
$$

Temperature element $(\mathrm{Ft})$ is considered that the greatest hazard to personnel is when fluids operate at high or low temperatures (Table 2). Items where temperatures are in excess of $70^{\circ} \mathrm{C}$ would be expected to cause injury to personnel if contacted, and similarly, temperatures $<-10^{\circ} \mathrm{C}$ (applicable to gas releases, where Joules-Thomson auto-refrigeration occurs on pressure drop or areas with liquefied gas containment). A high personnel risk has been assigned for temperature $<-10^{\circ} \mathrm{C}$ and above $70^{\circ} \mathrm{C}$. Pressure element (Fp) considered that the hazard from a loss of containment is proportional to the pressure of the system involved. The following pressure factors (Table 2) have been applied in this assessment. Inventory element (Fi) considered that hazard from a loss of containment is proportional to the perceived flammability, toxicity, and type (vapor/liquid and etc.) of the inventory involved. Inventory risk factor elements for all inventories must be determined by process optimization department and valued from 1 to 5 (e.g., air and water are 1, acid and caustic are 3, and process gas or cracked gas is 5). Inventory size element (Fis) considered that the greatest hazard to personnel exists with the release of the highest available amount of flammable inventory. This assessment assumes that if a leak were to occur in any item (transmission flow line, pipework, or vessel), all available inventories within a particular ESDV or control valve, envelope is available for release. The following temperature element $(\mathrm{Ft})$, pressure element (Fp), and inventory size elements (Table 2) have been utilized in this method:

Table 2: Temperature, pressure, and inventory size elements risk assessment

\begin{tabular}{lll}
\hline Items & Ranges & Consequence \\
\hline Temperature $\left({ }^{\circ} \mathrm{C}\right)$ & $\mathrm{T}<-10, \mathrm{~T}>70$ & 2 \\
& $-10 \leq \mathrm{T} \leq 70$ & 1 \\
Pressure (brag) & $\mathrm{p} \geq 30$ & 5 \\
& $10 \leq \mathrm{p}<30$ & 4 \\
& $5 \leq \mathrm{p}<10$ & 3 \\
& $0.5 \leq \mathrm{p}<5$ & 2 \\
& $\mathrm{p}<0.5$ & 1 \\
& $\mathrm{~V} \geq 5000$ & 2 \\
Inventory size element $(\mathrm{I})$ & $500 \leq \mathrm{V}<5000$ & 1.9 \\
& $50 \leq \mathrm{V}<500$ & 1.8 \\
& $20 \leq \mathrm{V}<50$ & 1.6 \\
& $\mathrm{~V}<20$ & 1.4 \\
& $\mathrm{~V}=0^{*}$ & 1 \\
\hline
\end{tabular}

\section{Pollution consequence factor (Cpol.)}

The consequences associated with pollution refers to the time after the loss of containment occurs and the pollution inventory is released to the atmosphere, i.e., when a polluted liquid leak overfills deck drains and bunds and enters the ground and natural drains are considered as a pollution consequence. After the pollution gas released to the atmosphere, the risk related to pollution relies on its impact on human and fauna. Pollution risk factor element (Cpol) for all inventories was determined by process optimization department and valued from 0 to 2 (e.g., air and water are 0 , acid and caustic are 2, and process gas is 1 ).

\section{Production consequence factor (Cprod.)}

The production consequence risk ranking (Cprod) refers to the effect of the failure of a particular item on production. It is the product of two factors, as shown below:

$$
\text { Cprod }=\text { Frep. Fop }(\max \text { value }=6)
$$


Where Frep is a repair factor and ranges from 1 to 2 and Fop is operability factor and ranges from 1 to 3 . Frep depends on the complexity of repairing an item that has failed due to corrosion; values of Frep have assigned as in Table 3.

Table 3: Repair factor

\begin{tabular}{lll}
\hline Item affected & & Repair factor (Frep) \\
\cline { 1 - 2 } Description & Characteristic & \\
\hline Pressure vessel & PWHT & 2.0 \\
& Not PWHT & 1.8 \\
Pipework & PWHT - all diameters & 2.0 \\
& Not PWHT - diameters 12" and higher & 1.8 \\
& Not PWHT - over 2" and up to 12" & 1.6 \\
& 2" and below & 1.3 \\
Transmission flow line & As welded or PWHT all diameters & 2.0 \\
\hline PWHT: Post-weld heat treatment.
\end{tabular}

Fop refers to the period of time that takes to the failed item to remain in shut down status until it has repaired and/or replaced. This could result in a significant loss of production. The effect of the failure on production is taken into account by the operability factor (Fop) supplied in Table 4. This covers three possible cases.

Table 4: Operability factor

\begin{tabular}{ll}
\hline Effect on production & Operability factor (Fop) \\
\hline No production possible (any event leading to a total shutdown) & 3 \\
Loss in production (partial or system shutdown involving & 2 \\
some deferment) & \\
No effect (events which do not result in deferment) & 1 \\
\hline
\end{tabular}

\section{Assessing LOF}

In an RBI program, the likelihood analysis is conducted to estimate the likelihood of a specific consequence resulting from a loss of containment. The LOC usually occurs due to degradation mechanism(s). According to API 581 standard, the likelihood factor is the sum of six factors, including (1) Remaining life factor (RLF), (2) damage factor (DF), (3) inspection factor (IF), (4) condition factor (CCF), (5) process factor (PF), and (6) mechanical design factor (MDF). Thereupon, the LOF category is determined as below:

$$
\mathrm{LOF}=\mathrm{RLF}+\mathrm{DF}+\mathrm{IF}+\mathrm{CCF}+\mathrm{PF}+\mathrm{MDF}
$$

The likelihood category is determined from the likelihood factor using the following logic:

- If likelihood factor is 0-15: Likelihood category is 1

- If likelihood factor is 16-25: Likelihood category is 2

- If likelihood factor is 26-35: Likelihood category is 3

- If likelihood factor is 36-50: Likelihood category is 4

- If likelihood factor is 51-75: Likelihood category is 5 .

\section{$R L F$}

API 581 standard was used to calculate LOF of the six main factors; one of these factors called equipment factor (EF) for this project is not applied. Since it is related to the macro scale of calculating risk on a scale between units or between organizations and has been ineffective on the scale of equipment in this project. This deficiency leads to design and calculate a new factor, which is going to be called as RLF. This factor shows the relationship between remaining life and rising risk.

The RLF is an estimated measure of the risk associated with a useful life of equipment's or piping taking into account wall thickness reduction, crack, or other damage mechanisms which can cause to an end for that item. Corrosion rate and remaining life will be calculated for each object as below:

$$
\begin{gathered}
C R=\left(t_{o}-t_{a}\right) / T \\
R L=\left(t_{a}-t_{\text {min }}\right) / C R
\end{gathered}
$$

Where, $t_{o}$ is original thickness $(\mathrm{mm}), t_{a}$ is last actual thickness $(\mathrm{mm}), \mathrm{T}$ is time between last thickness measurement and original thickness measurement (year), $t_{\min }$ is minimum wall thickness $(\mathrm{mm})$, or $\mathrm{t}_{\min }=(\mathrm{tn}-\mathrm{CA})$, where $\mathrm{tn}$ is nominal thickness and CA is corrosion allowance (Table 5).

Table 5: Remaining life factor

\begin{tabular}{ll}
\hline $\mathrm{RL}$ & $\mathrm{RLF}$ \\
\hline $\mathrm{RL}<5$ & 15 \\
$5 \leq \mathrm{RL}<10$ & 10 \\
$10 \leq \mathrm{RL}<20$ & 5 \\
$20 \leq \mathrm{RL}$ & 0 \\
\hline $\mathrm{RLF}:$ Remaining life factor. &
\end{tabular}

\section{DF}

The DF is a measure of the risk associated with common damage mechanisms that are either active or potentially active in operation. The mechanisms are categorized based on their potential to cause serious incidents. Therefore, to determine the DF following recommendations will be applied (Table 6):

\section{Table 6: Damage factor}

\begin{tabular}{lll}
\hline DF & Definition & Score \\
\hline DF1 & $\begin{array}{l}\text { If there are known, active damage mechanisms that can cause corrosion } \\
\text { cracking in carbon or alloy steels }\end{array}$ & 5 \\
DF2 & $\begin{array}{l}\text { If there is a potential for catastrophic brittle failure } \\
\text { If there are placed in the unit where mechanically thermally-induces } \\
\text { fatigue failure has occurred }\end{array}$ & 4 \\
DF4 & $\begin{array}{l}\text { If there is known high-temperature hydrogen attack occurring } \\
\text { If there is known corrosion cracking of austenitic stainless steels occurring }\end{array}$ & 3 \\
DF5 & 3 \\
DF6 & $\begin{array}{l}\text { If localized corrocess } \\
\text { DF7 }\end{array}$ & 3 \\
If general corrosion is occurring & $\begin{array}{l}\text { If creep damage is known to be occurring in high-temperature process, } \\
\text { including furnaces and heaters }\end{array}$ & 1 \\
DF9 & $\begin{array}{l}\text { If material degradation is known to be occurring, with such mechanism as as } \\
\text { sigma phase formation, carburization, spheroidization }\end{array}$ & 1 \\
DF10 & $\begin{array}{l}\text { If other active damage mechanisms have been identified } \\
\text { If potential damage mechanism in the operating unit has not been evaluated } \\
\text { and is not being periodically reviewed by a qualified material engineer }\end{array}$ & 1 \\
\hline DF: Damage factor. & 10
\end{tabular}

\section{IF}

The IF aims to measure the effectiveness of the inspection program to identify the active or anticipated damage mechanisms in the unit. Therefore, the following recommendations are applied for IF, as per Table 7: 
Table 7: Inspection factor

\begin{tabular}{lll}
\hline & Definition & Score \\
\hline Vessel inspection & $\begin{array}{l}\text { The inspection program is extensive (use of a variety of } \\
\text { inspection methods) } \\
\text { If there is a formal inspection program in place (visual and }\end{array}$ & -5 \\
UT thickness reading) & -2 \\
If there is no formal inspection program in place & 0 \\
Piping inspection & $\begin{array}{l}\text { The inspection program is extensive (use of a variety of } \\
\text { inspection methods) } \\
\text { If there is a formal inspection program in place (visual and }\end{array}$ & -5 \\
$\begin{array}{l}\text { UT thickness reading) } \\
\text { If there is no formal inspection program in place }\end{array}$ & 0 \\
Overall inspection & $\begin{array}{l}\text { If deterioration mechanism has been identified for each } \\
\text { program } \\
\text { equipment item and the inspection program is modified } \\
\text { based on the result of the program using a competent } \\
\text { inspector or materials engineer }\end{array}$ & -5 \\
If the inspection program design excludes either \\
identification of failure mechanisms or does not include \\
$\begin{array}{l}\text { critical evaluation of all inspection results, i.e., it does one } \\
\text { or the other, but not both } \\
\text { If Inspection program meets neither of the criteria of the } \\
\text { previous paragraph }\end{array}$
\end{tabular}

\section{CCF}

The CCF is intended to measure the effectiveness of plant maintenance and housekeeping efforts. Therefore, to explain, the IF following recommendations are used (Table 8):

\section{Table 8: Condition factor}

\begin{tabular}{lc}
\hline Definition & Score \\
\hline In a plant walkthrough, how would the plant housekeeping is judged (including painting \\
and insulation maintenance program)? & 0 \\
Significantly better than industry standards & 2 \\
Almost close industry standards & 5 \\
Significantly below the industry standards & 0 \\
The quality of plant design and construction is & 2 \\
Significantly better than industry standards & 5 \\
About industry standards & \\
Significantly below the industry standards & \\
In a review of the effectiveness of the plant maintenance program, & \\
including fabrication, PM programs, and QA/QC, they would be judged; &
\end{tabular}

\section{PF}

$\mathrm{PF}$ is a measure to indicate the abnormal operations or upset conditions which are prone to loss of containment events. Therefore, the below recommendations were taken into account to define the PF (Table 9):

\section{Table 9: Process factor}

\begin{tabular}{lc}
\hline Definition & Score \\
\hline The number of planned or unplanned process interruptions in an average year & \\
$0-1$ interruption & 0 \\
$2-4$ interruptions & 1 \\
$5-8$ interruptions & 3 \\
$9-12$ interruptions & 4 \\
More than 12 interruptions & 5 \\
Assess the potential for exceeding key process variables in operation being evaluated \\
If process is extremely stable, and no combination of the upset condition is known & 0 \\
If only very unusual circumstances could cause upset conditions to escalate & 1 \\
into an unsafe situation & \\
If upset conditions are known to exist that can result in accelerated equipment & 3 \\
damage or other unsafe conditions & 5 \\
If possibility of loss of control is inherent in the process & \\
Assess the potential for protection devices, such as relief devices and critical sensing elements \\
Clean service, no plugging potential & 0 \\
Slight; fouling or plugging potential & 1 \\
Significant fouling or plugging potential & 3 \\
Protective devices have been found impaired in service & 5 \\
\hline
\end{tabular}

\section{MDF}

MDF refers to certain aspects of the design of operating equipment, as per Table 10.
Table 10: Mechanical design factor

\begin{tabular}{|c|c|}
\hline $\begin{array}{l}\text { Definition } \\
\text { Step 1 }\end{array}$ & Score \\
\hline $\begin{array}{l}\text { If equipment can be identified that was not designed to the intent of current } \\
\text { codes or standards }\end{array}$ & 5 \\
\hline $\begin{array}{l}\text { If all equipment being considered in designed and maintained to the codes } \\
\text { in effect at the time, it was constructed }\end{array}$ & 2 \\
\hline $\begin{array}{l}\text { If all equipment being considered is designed and maintained to current } \\
\text { codes }\end{array}$ & 0 \\
\hline \multicolumn{2}{|l|}{ Step 2} \\
\hline $\begin{array}{l}\text { If the process being evaluated is unusual or unique or any of the process } \\
\text { design conditions are extreme }\end{array}$ & 0 \\
\hline About industry standards & 2 \\
\hline If the process is common, with normal design conditions & 5 \\
\hline
\end{tabular}

\section{Risk evaluation or risk ranking}

Throughout a plant or process unit, riskranking methodologies that apply consequence and probability categories, presenting the results in a risk matrix, are extremely effective to express the distribution of risks. An example risk matrix is shown in Figure 3. In this figure, the consequence and probability categories are arranged such that the highest risk ranking is toward the upper righthand corner. Regardless of the matrix selected, the consequence and probability categories should provide sufficient discrimination between the items assessed. Risk categories may be assigned to the boxes on the risk matrix. In this example, the risk categories are symmetrical. The results of RBI assessment will be used as a basis for the development of an overall inspection strategy.

\begin{tabular}{lllllll}
\hline LOF & 5 & $\mathrm{H}(1)$ & $\mathrm{H}(2)$ & $\mathrm{H}(3.5)$ & $\mathrm{E}(4)$ & $\mathrm{E}(5)$ \\
& 4 & $\mathrm{M}(0.8)$ & $\mathrm{M}(1.6)$ & $\mathrm{H}(2.4)$ & $\mathrm{H}(3.2)$ & $\mathrm{E}(4)$ \\
& 3 & $\mathrm{~L}(0.6)$ & $\mathrm{M}(1.2)$ & $\mathrm{M}(1.8)$ & $\mathrm{H}(2.4)$ & $\mathrm{E}(3)$ \\
& 2 & $\mathrm{~L}(0.4)$ & $\mathrm{L}(0.8)$ & $\mathrm{M}(1.2)$ & $\mathrm{M}(1.6)$ & $\mathrm{H}(2)$ \\
& 1 & $\mathrm{~N}(0.2)$ & $\mathrm{L}(0.4)$ & $\mathrm{L}(0.6)$ & $\mathrm{M}(0.8)$ & $\mathrm{H}(1)$ \\
& 0.2 & 0.4 & 0.6 & 0.8 & 1 \\
\hline
\end{tabular}

Figure 3: Schematic of RBI matrix (E: Extreme, H: High, M: Medium, L: Low, N: Negligible)

\section{Inspection plan}

The results of $\mathrm{RBI}$ assessment are going to be used as a basis for the development of an overall inspection plan. In this work, inspection classification as per inspection grade and risk-rank is presented in Table 11. It indicates the maximum inspection interval for a component; therefore, an appropriate grade should be selected. It should be noted that the maximum interval for each inspection grade only acts as a guideline and each of separately assessed components/equipment taken all previous history and information into account to determine the inspection frequency. After the equipment risk score is obtained, an approach is required to determine the inspection time schedule and, subsequently, the development of an inspection plan. How to select the inspection grade is given in Table 11. For example, inspection grade 1 means that no inspections have already been carried out on the equipment or that there is no proper inspection history. 
Table 11: COF and LOF results

\begin{tabular}{|c|c|c|c|c|c|c|c|c|c|c|c|c|c|c|c|c|}
\hline No. & Equipment & \multicolumn{5}{|c|}{ Consequence of failure } & \multicolumn{9}{|c|}{ Likelihood of failure } & Risk \\
\hline 1 & 30-D-406 & 2 & 3.2 & 6 & 0.93 & $\mathrm{E}$ & 0 & 5 & -4 & 6 & 2 & 0 & 0 & 9 & 1 & $\mathrm{H}$ \\
\hline 2 & $30-E-420$ & 2 & 2.43 & 6 & 0.87 & $\mathrm{E}$ & 0 & 5 & -4 & 6 & 2 & 0 & 0 & 9 & 1 & $\mathrm{H}$ \\
\hline 3 & $30-E-421$ & 2 & 1.60 & 5.4 & 0.75 & $\mathrm{H}$ & 0 & 5 & -4 & 6 & 2 & 0 & 5 & 14 & 1 & M \\
\hline 4 & $30-E-422 A$ & 2 & 2.56 & 2 & 0.55 & M & 0 & 6 & -4 & 6 & 9 & 0 & 5 & 22 & 2 & M \\
\hline 5 & $30-E-422 B$ & 2 & 1.28 & 2 & 0.44 & M & 0 & 5 & -4 & 6 & 9 & 0 & 5 & 21 & 2 & M \\
\hline 6 & $30-E-423$ & 1 & 3.04 & 5.4 & 0.79 & $\mathrm{H}$ & 0 & 5 & -4 & 6 & 2 & 0 & 0 & 9 & 1 & M \\
\hline 7 & $30-E-424$ & 1 & 1.60 & 5.4 & 0.67 & $\mathrm{H}$ & 0 & 5 & -4 & 6 & 5 & 0 & 0 & 12 & 1 & M \\
\hline 8 & $30-E-425$ & 1 & 3.20 & 5.4 & 0.80 & $\mathrm{H}$ & 0 & 5 & -4 & 6 & 2 & 0 & 0 & 9 & 1 & M \\
\hline 9 & $30-E-426$ & 0 & 0.64 & 1.8 & 0.20 & L & 0 & 5 & -4 & 6 & 1 & 0 & 0 & 8 & 1 & L \\
\hline 10 & $30-E-430$ & 2 & 1.28 & 3.6 & 0.57 & M & 5 & 0 & -4 & 6 & 3 & 0 & 0 & 10 & 1 & L \\
\hline 11 & $30-E-433$ & 1 & 3.04 & 5.4 & 0.79 & $\mathrm{H}$ & 0 & 5 & -4 & 6 & 3 & 0 & 10 & 20 & 2 & M \\
\hline 12 & $30-R-401 \mathrm{~A}$ & 2 & 3.20 & 2 & 0.60 & M & 0 & 5 & -4 & 6 & 4 & 0 & 0 & 11 & 1 & L \\
\hline 13 & $30-R-401 \mathrm{~B}$ & 2 & 3.20 & 2 & 0.60 & M & 0 & 5 & -4 & 6 & 4 & 0 & 0 & 11 & 1 & L \\
\hline 14 & 30-T-402 & 2 & 3.20 & 6 & 0.93 & E & 5 & 5 & -4 & 6 & 5 & 0 & 0 & 17 & 2 & $\mathrm{H}$ \\
\hline 15 & 30-D-412 & 1 & 0.08 & 1.8 & 0.24 & L & 0 & 5 & -4 & 6 & 1 & 0 & 0 & 8 & 1 & L \\
\hline 16 & C2-P-0001 & 1 & 0.60 & 5.4 & 0.58 & M & 0 & 5 & -6 & 6 & 2 & 7 & 2 & 16 & 2 & M \\
\hline 17 & C2-P-0002 & 1 & 0.64 & 5.4 & 0.58 & M & 0 & 5 & -6 & 6 & 2 & 7 & 2 & 16 & 2 & M \\
\hline 18 & C2-P-0003 & 1 & 0.57 & 5.4 & 0.58 & M & 0 & 5 & -6 & 6 & 2 & 7 & 2 & 16 & 2 & $M$ \\
\hline 19 & C2-P-0004 & 1 & 0.60 & 5.4 & 0.58 & M & 0 & 5 & -6 & 6 & 2 & 7 & 2 & 16 & 2 & $M$ \\
\hline 20 & C2-P-0005 & 1 & 0.64 & 5.4 & 0.58 & M & 0 & 5 & -6 & 6 & 2 & 7 & 2 & 16 & 2 & M \\
\hline 21 & C2-P-0006 & 1 & 0.30 & 5.4 & 0.55 & M & 0 & 5 & -6 & 6 & 2 & 7 & 2 & 16 & 2 & M \\
\hline 22 & C2-P-0007 & 1 & 0.64 & 5.4 & 0.58 & M & 0 & 5 & -6 & 6 & 2 & 7 & 2 & 16 & 2 & M \\
\hline
\end{tabular}

COF: Consequence of failure, LOF: Likelihood of failure, RLF: Remaining life factor. DF: Damage factor, IF: Inspection factor, CCF: Condition factor, PF: Process factor, MDF: Mechanical design factor.

\section{Results}

An expert team consisting of multi-disciplinary individuals, including operation manager, the RBI team leader, operations process specialist, production specialist, maintenance specialist, material (corrosion) specialist, equipment inspector, and representatives of the HSE, was gathered to elaborate development of the RBI procedure. The collected required information was collected from three different sources, including (1) the extracted data from design and manufacturing documents, (2) process data, and (3) repair records. The mentioned data sources of maintenance and inspection for the studied equipment parts, i.e., de-ethanizer section, are stored in a spreadsheet, i.e., excel database.

According to the results of the COF, it was found that $13.63 \%$ of the failure rate was at very high levels, $22.72 \%$ at high levels, $54.54 \%$ at a moderate level, and $9.09 \%$ at low levels. It was also found that the highest failure rate was related to de-ethanizer feed pre-heater (E-420), de-ethanizer reflux drum (D-406), and de-ethanizer tower (T-402). In addition, the lowest failure rate refers to nitrogen pre-heater (E-426) and reactor regeneration effluent cooler drum (D-412). Furthermore, due to the presence of water vapor, the lowest pollution factor was related to nitrogen pre-heater (E-426), and the highest rate of safety factor was related to de-ethanizer reflux drum (D-406), de-ethanizer feed pre-heater (E-420), and de-ethanizer tower (T-402). In terms of the production factor, important equipment is de-ethanizer reflux drum (D-406), C2 hydrogenation cooler (E-425), $C 2$ hydrogenation reactors (R-401 A/B), and de-ethanizer tower (T-402).

According to the results of the LOF, it was found that $50 \%$ of the equipment failure were placed in category 1 and $50 \%$ of equipment are classified in category 2. The de-ethanizer reboilers (E-422 A/B) and $\mathrm{C} 2$ hydrogenation pre-heaters $(\mathrm{E}-433 \mathrm{~A} / \mathrm{B})$ as well as de-ethanizer tower (T-402) are recognized as the most vulnerable equipment to be damaged. The role of process and experimental factors in determining the category of equipment is tangible.

The obtained risk ranking results in terms of factors for the consequence and LOF are presented in Table 12, which final column shows the classification of the consequence with the help of the outcome classification guide, presented in Table 1.

Table 12: Risk level results

\begin{tabular}{lllll}
\hline No. & Equipment tag & Risk & Inspection grade & Interval \\
\hline 1 & $30-\mathrm{D}-406$ & $\mathrm{H}$ & 2 & 48 \\
2 & $30-\mathrm{E}-420$ & $\mathrm{H}$ & 2 & 48 \\
3 & $30-\mathrm{E}-421$ & $\mathrm{M}$ & 2 & 72 \\
4 & $30-\mathrm{E}-422 \mathrm{~A}$ & $\mathrm{M}$ & 1 & 48 \\
5 & $30-\mathrm{E}-422 \mathrm{~B}$ & $\mathrm{M}$ & 1 & 48 \\
6 & $30-\mathrm{E}-423$ & $\mathrm{M}$ & 2 & 72 \\
7 & $30-\mathrm{E}-424$ & $\mathrm{M}$ & 2 & 72 \\
8 & $30-\mathrm{E}-425$ & $\mathrm{M}$ & 2 & 72 \\
9 & $30-\mathrm{E}-426$ & $\mathrm{~L}$ & 1 & 60 \\
10 & $30-\mathrm{E}-430$ & $\mathrm{~L}$ & 2 & 90 \\
11 & $30-\mathrm{E}-433$ & $\mathrm{M}$ & 2 & 72 \\
12 & $30-\mathrm{R}-401 \mathrm{~A}$ & $\mathrm{~L}$ & 2 & 90 \\
13 & $30-\mathrm{R}-401 \mathrm{~B}$ & $\mathrm{~L}$ & 2 & 90 \\
14 & $30-\mathrm{T}-402$ & $\mathrm{H}$ & 2 & 48 \\
15 & $30-\mathrm{D}-412$ & $\mathrm{~L}$ & 2 & 90 \\
16 & $\mathrm{C}-\mathrm{P}-0001$ & $\mathrm{M}$ & 1 & 72 \\
17 & $\mathrm{C}-\mathrm{P}-0002$ & $\mathrm{M}$ & 1 & 72 \\
18 & $\mathrm{C} 2-\mathrm{P}-0003$ & $\mathrm{M}$ & 1 & 72 \\
19 & $\mathrm{C} 2-\mathrm{P}-0004$ & $\mathrm{M}$ & 1 & 72 \\
20 & $\mathrm{C}-\mathrm{P}-0005$ & $\mathrm{M}$ & 1 & 72 \\
21 & $\mathrm{C} 2-\mathrm{P}-0006$ & $\mathrm{M}$ & 1 & 72 \\
22 & $\mathrm{C} 2-\mathrm{P}-0007$ & $\mathrm{M}$ & 1 & \\
\hline
\end{tabular}

According to the results of the risk assessment of the understudy equipment, it was found that $13.6 \%$ of the equipment expose a high-risk level, $63.63 \%$ with a moderate risk level, and $22.72 \%$ with a low-risk level. In this study, in spite of the high-risk level of (T-402) tower and (D-406) drum, the (E-420) heat-exchanger also has a high-risk score. The main reason for this is the high failure probability of these items. Equipment with risk ranks of 1 and 2 have a high level of risk mainly due to lack of proper history associated with inspection, for example, some of the equipment did not have a history of inspection and some had a one-time inspection record. In this case, if the level of risk of equipment is moderate and the inspection grade is 1 , the first inspection period is 48 months, and the 
second inspection if the failure is not detected in the first inspection along with a continuous inspection plan, it changes to 72 months.

Regarding the results of risk assessment, we can use Figure 4 to better understand the frequency distribution of equipment inspection in different years. This chart helps us to make the final decision about the overhaul time, as well as guidance to examine the equipment that should be managed under risk management.

\begin{tabular}{|c|c|c|c|c|c|c|c|}
\hline & \multicolumn{5}{|c|}{ Risk Rank } & \\
\hline & & 1 & 2 & 3 & 4 & 5 & \\
\hline \multirow{4}{*}{ 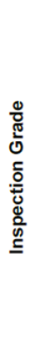 } & 1 & 72 & 60 & 48 & 36 & 24 & $\begin{array}{l}\text { * No previous inspection history, or } \\
\text { * Inadequate inspection history. }\end{array}$ \\
\hline & 2 & 96 & 90 & 72 & 48 & 36 & $\begin{array}{l}\text { " At least } 1 \text { previous inspection, and } \\
\text { " No deterioration found. }\end{array}$ \\
\hline & 3 & 120 & 120 & 96 & 72 & 48 & $\begin{array}{l}\text { " At least } 2 \text { previous inspection. } \\
\text { " At least } 1 \text { previous RBI inspection and } \\
\text { * No unexpected deterioration found. }\end{array}$ \\
\hline & 4 & 120 & 120 & 120 & 96 & 60 & $\begin{array}{l}\text { " At least } 3 \text { previous inspection. } \\
\text { " At least } 2 \text { previous RBI inspection and } \\
\text { * Only predictable deterioration found. }\end{array}$ \\
\hline
\end{tabular}

Figure 4: Relationship between risk rank and inspection grade

The level of risk for the equipment highlighted in yellow needs to be reduced before 2015 to enable them to be inspected in 2015 and has an acceptable level of risk at that time. Equipment highlighted in green will be capable to be delivered for inspection in normal operation time and in the same year without stopping the unit (Figure 5).

\begin{tabular}{lllllll}
\hline 7 & & C2-P-0006 & & \\
6 & & & C2-P-0007 & & \\
5 & & & $30-E-421$ & $30-D-412$ & \\
4 & $30-D-406$ & & $30-E-423$ & $30-E-430$ & \\
3 & $30-E-420$ & & $30-E-424$ & $30-R-401$ A & \\
2 & $30-E-426$ & $30-E-422 A$ & $30-E-425$ & $30-R-401$ B & \\
1 & $30-T-402$ & $30-E-422 B$ & $30-E-433$ & 2018 & 2018 \\
& 2013 & 2014 & 2015 & 2017 & \\
\hline
\end{tabular}

Figure 5: Frequency distribution of equipment inspection in different years

Since the introduction of the RBI method, it has found its place in the international oil, gas, and petrochemical companies, and there have been many studies in this regard. In the oil, gas, and petrochemical industry of Iran, the application of this method has recently been considered, but unfortunately, it has not found its place in the form of an executive instruction.

This study was conducted on all equipment of a process unit as a group (de-ethanizer Unit), which is of high importance compared to other studies that have only focus on a single equipment.

\section{Discussion}

RBI could have both qualitative and quantitative procedure that combines the probability and the COF to create a prioritized list for equipment based on their risk. Three types of RBI have been established by API for ranking risk levels. Type I is qualitative RBI which uses a simple format to risk rank process equipment into a 5 rdpite of high-risk level semi-quantitative RBI, which is an intermediate methodology of quantitative RBI (Type III). Type II similarly applies a five by five risk matrix for demonstrating risk study results. Type III is quantitative RBI which is a more comprehensive (and more accurate) technique of risk classification for individual parts of equipment in a process unit. The applied methodology in this study is compiled from the possibility of equipment failure from the API 581 standard and the consequence of the failure equipment from the specific process unit in ASPC. Implementing this method in process units is much easier, more practical, and more cost-effective than existing tools.

This study was conducted on all equipment of a specific process unit, which has a higher value compared to other studies that are solely unique to one or more separate equipment [11], [22], [23]. The results of this type of research will help us to determine the more proper time of the overhauls for the under-study unit, particularly for a case such as an exchanger to determine whether to change the overhaul time or not. Furthermore, the results could be used to determine the high-risk equipment in each unit in terms of resource allocation.

According to API 581 standard, to calculate LOF, six main factors are applied, one of these factors called the EF. This factor in the present project was not applied. Since it is related to the macro scale of calculating risk on a scale between units or between organizations and has been ineffective on the scale of equipment. This disadvantage led to the design and calculation of a replacement factor called the RLF. This factor demonstrates the relationship between remaining life and rising risk. It should be noticed that this approach has not been taken into account in any other previously performed studies.

In most industrial units, more than $80 \%$ of the entire unit's risk is related to only $20 \%$ of its equipment and components [24]. This is proved by the results of this study that the classified equipment into five different levels of risk rating. In this study, the number obtained for high-risk equipment is $13.6 \%$, which will help us focus resources (inspection, maintenances, and manpower costs) on only $10 \%$ to $20 \%$ of highrisk equipment. It is worth recalling that the results are consistent with the previous studies mentioned in the research background [7], [25], [26], [27].

In all previous studies, identified risks have been considered from a safety point of view and economic interest has not been taken into account the issue of safe and optimal production [1], [11], [28]. In this study, special attention has been paid on safety, production, and contamination. For this purpose, the weights of each one are considered in the calculation of the consequence of the failure depending on its importance. 
The study has led to reduce the number of annual overhauls and postponed it from 2013 to 2015. As a result, the cost of loss of production for major repairs, inspection, and manpower was significantly reduced. That resulted in saving of $\$ 69,000,000$ (based on the world price of $\$ 1200$ per ton of ethylene and a production ceiling of 120 tons $/ \mathrm{h}$ ) due to avoidance of stopping the production for 20 days/year and $\$$ 1.5 million for performed routine major repairs and inspections.

\section{Conclusion}

$\mathrm{RBI}$ offers a logical, documented, repeatable approach for specifying the optimal inspection frequencies. RBI aims to confirm the emphasis of inspection on fields with high risk, while inspection in fields with low risk will also be reduced or excluded from the ordinary inspection plan and consequently result in important inspection and maintenance cost decrease. The use of $\mathrm{RBI}$ would be very useful for Iranian Industry, because the management of risk, and costs of inspection and understanding failure processes, and mitigation mechanisms, would be created. Application of $\mathrm{RBI}$ would be useful in improving health and safety, and reducing the risk of environmental hazards, and improve documented organization which can be continually developed and improved. The managersplication of RBlof RBI would be enhanced since the use of RBI will certainly have different advantages in terms of safety and saving maintenance costs in the organization. That must contain some activities such as training of personnel and considering some minor changes on procedures in management systems.

\section{References}

1. Tien SW, Hwang WT, Tsai CH. Study of a risk-based piping inspection guideline system. ISA Trans. 2007;46(1):119-26. https://doi.org/10.1016/j.isatra.2006.06.006

2. Khan FI, Haddara MM. Risk-based maintenance (RBM): A quantitative approach for maintenance/inspection scheduling and planning. J Loss Prev Process Ind. 2003;16(6):561-73. https://doi.org/10.1016/j.jp.2003.08.011

3. Apeland S, Scarf PA. A fully subjective approach to modelling inspection maintenance. Eur J Oper Res. 2003;148(2):410-25. https://doi.org/10.1016/s0377-2217(02)00356-9

4. Shin JH, Jun HB. On condition based maintenance policy. $J$ Comput Des Eng. 2015;2(2):119-27.

5. Florian M, Sørensen JD. Risk-based Planning of $O$ \& $M$ for Wind Turbines Using Physics of Failure Models. Bilbao, Spain: Proceedings of the $3^{\text {rd }}$ European Conference of the Prognostics and Health Management Society; 2016.

6. Poulassichidis T. Application of Risk Based Inspection to
Offshore Facilities. United States: SPE Annual Technical Conference and Exhibition, Society of Petroleum Engineers: 2009. https://doi.org/10.2118/124539-ms

7. Chang MK, Chang RR, Shu CM, Lin KN. Application of risk based inspection in refinery and processing piping. J Loss Prev Process Ind. 2005;18(4-6):397-402. https://doi.org/10.1016/j. jlp.2005.06.036

8. Herzog BO, Jackson P. The Ladder to Success: Risk-based Inspection Reduces Costs. Switzerland: ABB Review; 2009. p. 1.

9. Drożyner P, Veith E. Risk based inspection methodology overview. Diagnostyka. 2002;27:82-8.

10. Jovanovic A. Risk-based inspection and maintenance in power and process plants in Europe. Nucl Eng Des. 2003;226(2):16582. https://doi.org/10.1016/j.nucengdes.2003.06.001

11. Shuai J, Han K, Xu X. Risk-based inspection for large-scale crude oil tanks. J Loss Prev Process Ind. 2012;25(1):166-75. https://doi.org/10.1016/j.jp.2011.08.004.

12. Coble JB, Coles GA, Meyer RM, Ramuhalli P. Incorporating Equipment Condition Assessment in Risk Monitors for Advanced Small Modular Reactors. United States: Chemical Engineering; 2013. p. 33. https://doi.org/10.2172/1077993

13. Reynolds JT. Risk Based Inspection-where Are We Today? United States: NACE International; 2000.

14. Jalili L, Khomami MS, Firuzabad MF, Dehhhanian $P$, Ghahnavieh A. Designing a Financially Efficient Risk-oriented Model for Maintenance Planning of Power Systems: A Practical Perspective. Maharashtra: $12^{\text {th }}$ International Conference on Probabilistic Methods Applied to Power Systems, PMAPS; 2012. https://doi.org/10.1109/pmaps.2016.7764220

15. Kallen MJ, van Noortwijk JM. Optimal maintenance decisions under imperfect inspection. Reliabil Eng Syst Saf. 2005;90(23):177-85. https://doi.org/10.1016/j.ress.2004.10.004

16. American Petroleum Institute. Risk-based Inspection. Washington, DC: American Petroleum Institute; 2002. https:// doi.org/10.1115/omae2004-51543

17. DNV. Recommended Practice DNV-RP-G101: Risk Based Inspection of Offshore Topsides Static Mechanical Equipment. Norway: DNV; 2010.

18. Kallen MJ. Risk Based Inspection in the Process and Refining Industry. Master's Thesis, Faculty of Information Technology and Science. Delft, Netherlands: Technical University Delft; 2002.

19. Khan Fl, Haddara M. Risk-based maintenance (RBM): A new approach for process plant inspection and maintenance. Process Saf Prog. 2004;23(4):252-65. https://doi.org/10.1002/ prs. 10010

20. Chien $\mathrm{CH}$, Chen $\mathrm{CH}$, Chao YJ. A strategy for the risk-based inspection of pressure safety valves. Reliabil Eng Syst Saf. 2009;94(4):810-8. https://doi.org/10.1016/j.ress.2008.09.002

21. Inspection RB. API Recommended Practice 580. United States: American Petroleum Institute; 2009

22. Nivolianitou Z, Argyropoulos C, Christolis M, Markatos N. A Methodology for the Hazard Assessment in Large Hydrocarbon Fuel Tanks. New York, United States: Chemical Engineering 2012. p. 26.

23. Simpson J. The Application of Risk Based Inspection to Pressure Vessels and Aboveground Storage Tanks in Petroleum Fuel Refineries. Australia: Proceedings of the $5^{\text {th }}$ Australasian Congress on Applied Mechanics; 2007.

24. Vesely W. Principles of resource-effectiveness and regulatoryeffectiveness for risk-informed applications: Reducing burdens by improving effectiveness. Reliabil Eng Syst Saf. 1999;63(3):28392. https://doi.org/10.1016/s0951-8320(98)00044-1

25. Lee SM, Chang YS, Choi JB, Kim YJ. Application of an enhanced $\mathrm{RBI}$ method for petrochemical equipments. J Press Vessel 
Technol. 2006;128(3):445-53. https://doi.org/10.1115/1.2218350

26. Vianello C, Maschio G, Mura A, Babolin D, Gambato F, Attori C. Development of a RBI Tool for Inspection Management in Chemical Plants. United States: Chemical Engineering Transactions; 2013. p. 31.

27. Song GW, Kim BS, Choi WS, Park MS. Prediction of maintenance period of equipment through risk assessment of thermal power plants. Trans Korean Soc Mech Eng A. 2013;37(10):1291-6. https://doi.org/10.3795/ksme-a.2013.37.10.1291

28. Wang G, Yan T, Zhang J, Chen J. Risk based inspection on the equipment of low density polyethylene. Procedia Eng. 2011;15:1145-8. https://doi.org/10.1016/j.proeng.2011.08.211 